Chapman University

Chapman University Digital Commons

Mathematics, Physics, and Computer Science

Science and Technology Faculty Articles and

Faculty Articles and Research

Research

2005

\title{
Inhibition Modifies the Effects of Slow Calcium- Activated Potassium Channels on Epileptiform Activity in a Neuronal Network Model
}

\author{
Keun-Hang Susan Yang \\ Chapman University, kyang@chapman.edu \\ Piotr J. Franaszczuk \\ Johns Hopkins University \\ Gregory K. Bergey \\ Johns Hopkins University
}

Follow this and additional works at: http://digitalcommons.chapman.edu/scs_articles
Part of the Animals Commons, Animal Structures Commons, Biochemistry Commons, and the Nervous System Commons

\section{Recommended Citation}

Yang, K-H., Piotr J. Franaszczuk, and Gregory K. Bergey. "Inhibition modifies the effects of slow calcium-activated potassium channels on epileptiform activity in a neuronal network model." Biological cybernetics 92.2 (2005): 71-81.

doi: $10.1007 / \mathrm{s} 00422-004-0532-0$

This Article is brought to you for free and open access by the Science and Technology Faculty Articles and Research at Chapman University Digital Commons. It has been accepted for inclusion in Mathematics, Physics, and Computer Science Faculty Articles and Research by an authorized administrator of Chapman University Digital Commons. For more information, please contact laughtin@chapman.edu. 


\section{Inhibition Modifies the Effects of Slow Calcium-Activated Potassium Channels on Epileptiform Activity in a Neuronal Network Model}

\section{Comments}

This is a pre-copy-editing, author-produced PDF of an article accepted for publication in Biological Cybernetics, volume 92, issue 2, 2005 following peer review. The final publication is available at Springer via DOI: $10.1007 /$ s00422-004-0532-0.

\section{Copyright}

Springer 


\title{
Inhibition Modifies the Effects of Slow Calcium-Activated Potassium Channels on Epileptiform Activity in a Neuronal Network Model
}

\author{
Keun-Hang Yang, Piotr J. Franaszczuk, and Gregory K. Bergey \\ Department of Neurology, Johns Hopkins Epilepsy Center, Johns Hopkins \\ University School of Medicine, Baltimore, Maryland
}

\begin{abstract}
Generation of epileptiform activity typically results from a change in the balance between network excitation and inhibition. Experimental evidence indicates that alterations of either synaptic activity or intrinsic membrane properties can produce increased network excitation. The slow $\mathrm{Ca}^{2+}$ - activated $\mathrm{K}^{+}$currents $\left(\mathrm{sI}_{\mathrm{AHP}}\right)$ are important modulators of neuronal firing rate and excitability and have important established and potential roles in epileptogenesis. While the effects of changes of $\mathrm{sI}_{\mathrm{AHP}}$ on individual neuronal excitability are readily studied and well established, the effects of such changes on network behavior are less well known. The experiments here, utilize a defined small network model of multicompartment pyramidal cells and an inhibitory interneuron, to study the effects of changes on $\mathrm{sI}_{\mathrm{AHP}}$ on network behavior. The benefits of this model system include the ability to observe activity in all cells in the network and the effects of interactions of multiple simulataneous influences. In the model with no inhibitory interneuron, increasing $\mathrm{sI}_{\mathrm{AHP}}$ results in progressively decreasing burst activity. Adding an inhibitory interneuron changes the observed effects; at modest inhibitory strengths, increasing $\mathrm{sI}_{\mathrm{AHP}}$ in all network neurons actually results in increased network bursting (except at very high values). The duration of the burst activity is influenced by the length of delay in a feedback loop, with longer loops resulting in more prolonged bursting. These observations illustrate that the study of potential antiepileptogenic membrane effects must be extended to realistic networks. Network inhibition can dramatically alter the observations seen in pure excitatory networks.
\end{abstract}




\section{Background and Significance}

Epileptiform activity is characterized by synchronized bursting of groups of neurons. This activity can result from a variety of mechanisms involving either intrinsic membrane properties or modulation of synaptic activity (Bernard et al., 2000; During et al., 1995; Olsen and Avoli, 1997; Treiman, 2001). A common feature to all models is a shift in the balance of excitation and inhibition to favor increased excitation, whether by decreasing synaptic inhibition, increasing synaptic excitation or direct effects on membrane excitability (Bernard et al., 2000; Freund and Buzsáki, 1996; Prince, 1978; Treiman, 2001). Understanding these various mechanisms can not only provide insights into causes of epileptogenesis, but also into potential therapeutic interventions. For instance, a number of existing antiepileptic drugs act to augment GABAergic inhibition or to affect (reduce) voltage dependent sodium conductance that underlies repetitive firing (Kwan et al., 2001; Moshe SL, 2000).

The array of potassium channels expressed by a neuron is a major factor in determining its excitability. Studies of human epileptic hippocampus indicate that changes in the properties of some potassium channels may contribute to neuronal hyperexcitability and epileptogenesis (Beck et al., 1996; Biervert et al., 1998; McBain, 1994; Verma-Ahuja et al., 1995). The slow $\mathrm{Ca}^{2+}-$ activated $\mathrm{K}^{+}$current $\left(\mathrm{sI}_{\mathrm{AHP}}\right)$ mediates the post-spike after hyperpolarization (AHP) that limits excitability of pyramidal neurons (Alger and Nicoll, 1980; Behr et al., 2000; Empson and Jefferys, 2001; Verma-Ajuja et al., 1995). Alger and Nicoll (1980) suggest that the $\mathrm{Ca}^{2+}$ dependent $\mathrm{K}^{+}$current is important in preventing the development of seizure-like activity. In addition, Empson and Jefferys (2001) suggest that $\mathrm{Ca}^{2+}$ entry through L-type $\mathrm{Ca}^{2+}$ channels activates a $\mathrm{K}^{+}$current that helps terminate epileptiform activity.

While the studies summarized above suggest that $\mathrm{sI}_{\mathrm{AHP}}$ controls the excitatory output of neuronal networks by altering intrinsic neuronal excitability, an unknown factor in these experiments is the role of interneurons. Interneurons also control the excitatory output of networks by providing feedback inhibition onto excitatory neurons. Interneurons, like pyramidal 
neurons, possess $\mathrm{sI}_{\mathrm{AHP}}$ (Zhang and McBain, 1995; McQuiston and Madison, 1999). In contrast to pyramidal neurons, reducing $\mathrm{SI}_{\mathrm{AHP}}$ and thereby increasing excitability in inhibitory interneurons might be expected to reduce rather than enhance the overall excitability of the network. When this added complexity is considered, it becomes less clear how various modulators may affect network behavior.

Biological models of epileptogenic activity are particularly suited to studies of the effects of various agents on intrinsic membrane properties and synaptic activity. Such models, however, also have limitations. Technical limitations influence the number and duration of simultaneous recordings from neurons in a given network. In addition the effects of various agents cannot be always exactly controlled or rapidly changed. Neuron circuit models allow for examinations of exactly controlled changes of membrane properties and synaptic connectivity with the ability to monitor all neurons within a given network. This permits the study of the influences of single or multiple simultaneous changes on resultant network behavior and synchronized bursting.

As mentioned above, the $\mathrm{sI}_{\mathrm{AHP}}$ is thought to play an important role in modulating neuronal and network excitability. The current study utilizes previously characterized small, multi-compartment models of pyramidal cells to study the influences of $\mathrm{sI}_{\mathrm{AHP}}$ on network excitability and repetitive bursting, but also the modulation of these influences by the presence and strength of local circuit inhibitory interneurons. The results obtained suggest that the potential antiepileptic effects of increasing network $\mathrm{sI}_{\mathrm{AHP}}$ can be significantly affected by these interneurons and indeed, in some instances network increases in $\mathrm{sI}_{\mathrm{AHP}}$ may actually result in increased rather than decreased network excitation as manifest by bursting activity.

\section{Methods}

We use a model of pyramidal cells from the previous study (Yang et al., 2003) using the simulation software GENESIS (http://www.genesis-sim.org/GENESIS/) and classify this pyramidal cell model into type I model and type II model. As described in the previous study 
(Yang et al., 2003), there are three simplified pyramidal neurons in the type I model: two neurons synaptically connected with excitatory synapses forming a loop (neuron 2 and neuron 3 in Fig. 1A), a neuron where random input is applied to generate action potentials (neuron 1 in Fig. 1A). The synaptic inputs on each main dendrite of two pyramidal neurons are connected by an excitatory synapse (Fig. 1A). In the type II model, an inhibitory interneuron is added to the type I model. This inhibitory interneuron (neuron 4 in Fig. 1B) is in a negative feedback loop with one of the modeled pyramidal neurons (neuron 3 in Fig. 1B). This inhibitory interneuron synapses on the main dendrites of neuron 3 (Fig. 1B).

Each pyramidal neuron with 17 compartments is comprised of a soma, a main dendrite, and two branch dendrites. The soma has a fast sodium channel $\left(\mathrm{I}_{\mathrm{Na}}\right)$, delayed potassium channel $\left(\mathrm{I}_{\mathrm{KDR}}\right)$, transient potassium channel $\left(\mathrm{I}_{\mathrm{A}}\right)$, high-threshold calcium channel $\left(\mathrm{I}_{\mathrm{Ca}}\right)$, and slow calcium activated potassium channel $\left(\mathrm{SI}_{\mathrm{AHP}}\right)$, and short-duration voltage and calcium dependent potassium channel $\left(\mathrm{I}_{\mathrm{KC}}\right)$. The equations for these channels are the same as in the Traub et al. $(1991,1994)$ multicompartmental CA3 pyramidal cell model. The inhibitory interneuron has a soma with the same channels as in the soma of the pyramidal neurons. The soma and dendrites have excitatory and inhibitory synapses, which connect two neurons by reciprocal excitatory synapses. The parameters for these excitatory and inhibitory synaptic conductance and cellular dimensions of the soma and dendrites are the same as in the reduced models of piriform cortex pyramidal cell in Protopapas et al. (1998). The soma also has a fast GABAergic and a slow GABAergic inhibitory channels. The kinetics of these fast and slow GABAergic components are the same as for $\mathrm{GABA}_{\mathrm{A}}$ inhibitory and $\mathrm{GABA}_{\mathrm{B}}$ inhibitory synapses, respectively, in a model of piriform cortex pyramidal cells (Protopapas et al., 1998).

The excitatory synaptic connection between neurons is modeled by a synaptic current, $\mathrm{I}_{\mathrm{syn}}$ (Bhalla and Bower, 1993). The synaptic conductance is modeled as an alpha function with the maximum value of $0.5 \mathrm{nS}$. The synaptic weight represents the overall strength of a connection and the synaptic delay represents all delays between neurons. Simulations were performed for 20 
sec using GENESIS version 2.2 on a LINUX operating system. The simulation time step is 0.05 ms, which is the same value as in the Traub et al. (1991, 1994) multicompartmental CA3 pyramidal cell model provided with GENESIS.

In order to examine the role of the $\mathrm{sI}_{\mathrm{AHP}}$ on bursting activity in the type I model, simulations were performed with a range of the channel conductance density of the $\mathrm{sI}_{\mathrm{AHP}}$ for the pyramidal neurons. The channel conductance density represents the conductance per unit area of the compartment. The area of the soma compartment is $4.398 \times 10^{-5} \mathrm{~cm}^{2}$. The channel conductance density of the $\mathrm{sI}_{\mathrm{AHP}}\left(\mathrm{g}_{\mathrm{sI}} \mathrm{AHP}=0.8 \mathrm{mS} / \mathrm{cm}^{2}\right)$ was chosen from a model of hippocampal pyramidal neurons (Traub et al., 1991). The channel conductance density of the GABA $\left(\mathrm{g}_{\mathrm{GABA}}=0.005\right.$ $\mathrm{mS} / \mathrm{cm}^{2}$ ) was calculated from the synaptic conductance value of $\mathrm{GABA}_{\mathrm{B}}$ in a model of piriform cortex pyramidal cells (Protopapas et al., 1998). These channel conductance densities, $\mathrm{g}_{\mathrm{sI}_{\mathrm{AHP}}}$ and $\mathrm{g}_{\mathrm{GABA}}$, were varied to confirm known properties of the $\mathrm{sI}_{\mathrm{AHP}}$ on neuronal excitability in the pyramidal neurons using the type I model. Then in the type II model, the $\mathrm{g}_{\mathrm{sI}} \mathrm{AHP}_{\mathrm{HP}}$ and $\mathrm{g}_{\mathrm{GABA}}$ were also varied to investigate the role of the $\mathrm{sI}_{\mathrm{AHP}}$ on bursting activity in a neuronal circuit model with the pyramidal and inhibitory neurons. These values of the $\mathrm{g}_{\mathrm{sI}} \mathrm{AHP}_{\mathrm{H}}$ and $\mathrm{g}_{\mathrm{GABA}}$ in the present study are to illustrate transitions to different levels of activity.

The duration of the bursts in the pyramidal neurons was investigated using the type II model. The channel conductance densities of the $\mathrm{sI}_{\mathrm{AHP}}$ and $\mathrm{GABA}\left(\mathrm{g}_{\mathrm{SI}_{\mathrm{AHP}}}\right.$ and $\left.\mathrm{g}_{\mathrm{GABA}}\right)$ that result in a short bursting activity with a loop delay, $2 \mathrm{msec}$, in the pyramidal neurons were chosen. With these $\mathrm{g}_{\mathrm{sI}} \mathrm{AHP}_{\mathrm{G}}$ and $\mathrm{g}_{\mathrm{GABA}}$, loop delays, representing all delays between the pyramidal neuron and inhibitory interneuron in a circuit, were varied. Different combinations of the excitatory and inhibitory delays, which produce the same loop delays, were applied to examine the sensitivity of the model to the loop delays.

The present study used the values of median or standard deviation of interspike intervals 
(ISIs) for examination of bursting patterns. We chose the value of the median of ISIs, $185 \mathrm{msec}$, as the lowest value for the definition of no bursting activity from previous studies (Yang et al., 2002 and 2003). The standard deviation value of ISIs of $30 \mathrm{msec}$ was the lowest value for the definition of bursting activity. Thus, we classified simulations that result in the median values of ISIs $\geq 185 \mathrm{msec}$ as no bursting activity, the standard deviation values of ISIs $<30 \mathrm{msec}$ as prolonged depolarization, and all others as bursting activity.

Figure 2 shows the classification of the patterns of bursting activity. The bursting patterns in these circuit models are classified into prolonged depolarization (PD), long bursts (LB), medium bursts $(\mathrm{MB})$, short bursts $(\mathrm{SB})$, and nonburst $(\mathrm{NB})$ patterns depending on duration of the bursts (Fig. 2). The prolonged depolarization has a burst for an entire simulation time, $19.6 \mathrm{sec}$. The long bursting activity has a few bursts with a duration range of the burst between $2.6 \mathrm{sec}$ and $6.6 \mathrm{sec}$. The medium and short bursting activity have more frequent bursts than the long bursting activity and include several bursts with a duration range of between $210 \mathrm{msec}$ and $400 \mathrm{msec}$, and $<200 \mathrm{msec}$, respectively. These criteria for classification of the patterns of bursting activity are used to define bursting behavior of the pyramidal neurons shown in Fig. 3.

\section{Results}

The present study with the circuit pyramidal cell models indicates that the $\mathrm{sI}_{\mathrm{AHP}}$ of the excitatory neuron or inhibitory interneuron regulates bursting activity. Figure 3 shows that changes in the channel conductance density of $\mathrm{GABA}$ or $\mathrm{sI}_{\mathrm{AHP}}$ can regulate bursting activity in type I and type II models. In the Type I model without the inhibitory interneuron, duration of the bursts decreases as the $\mathrm{sI}_{\mathrm{AHP}}$ conductance density is increased (the bottom panel in Fig. 3). The pyramidal neurons do not generate bursting activity when the $\mathrm{sI}_{\mathrm{AHP}}$ conductance density is 30.0 $\mathrm{mS} / \mathrm{cm}^{2}$ or greater. In the Type II model with the inhibitory interneuron, the pyramidal neurons generate bursting activity when the $\mathrm{sI}_{\mathrm{AHP}}$ conductance density in both the pyramidal neurons and 
inhibitory interneuron is $\geq 0.4 \mathrm{mS} / \mathrm{cm}^{2}$ and $\leq 8.0 \mathrm{mS} / \mathrm{cm}^{2}$ and the GABA conductance density in the pyramidal neurons is $<0.15 \mathrm{mS} / \mathrm{cm}^{2}$ (light gray area on the top panel in Fig. 3). However, when either the $\mathrm{sI}_{\mathrm{AHP}}$ conductance density in both pyramidal neurons and inhibitory interneuron is $<0.4 \mathrm{mS} / \mathrm{cm}^{2}$ or $>8.0 \mathrm{mS} / \mathrm{cm}^{2}$ with the same GABA conductance density, $<0.15 \mathrm{mS} / \mathrm{cm}^{2}$, there is no bursting activity (white area on the top panel in Fig. 3). When the GABA conductance density is increased to $0.15 \mathrm{mS} / \mathrm{cm}^{2}$ there is no busting activity for any values of the $\mathrm{sI}_{\mathrm{AHP}}$ conductance density.

Classification of the patterns of bursting activity is evaluated using the same interspike interval (ISI) analysis as used in Yang et al. (2003). In previous (Yang et al., 2003) and the present studies, we used ISI analysis to classify the patterns of bursting activity in the pyramidal neurons into burst, nonburst, and depolarized burst. The threshold values of the median and standard deviation for ISIs from the previous study (Yang et al., 2003) are used for classification of the patterns of bursting activity. Our simulations show that the criteria of the median and standard deviation ISI values for classification of the patterns of bursting activity from the previous study (Yang et al., 2003) are also applicable for the present study.

Figures 4 and 5 show the influence of changes in the values of the $\mathrm{sI}_{\mathrm{AHP}}$ conductance density on bursting activity in the pyramidal neurons. The top panel shows action potentials generated from random inputs in the pyramidal neuron 1 in Figure 1 . The middle panel shows trace of membrane potentials in the pyramidal neuron 3 in type II model (Fig. 1B). The bottom panel shows trace of membrane potentials in the inhibitory interneuron in Figure 1B. Figure 4 shows trace of membrane potentials with the value of the $\mathrm{sI}_{\mathrm{AHP}}$ conductance density, $0.1 \mathrm{mS} / \mathrm{cm}^{2}$, and the value of the GABA conductance density, $0.015 \mathrm{mS} / \mathrm{cm}^{2}$, in the pyramidal neuron and inhibitory interneuron when the total feedback loop delay is $2 \mathrm{msec}$. There is no bursting activity in the pyramidal neuron 3(middle panel) for these values of the $\mathrm{sI}_{\mathrm{AHP}}$ and GABA conductance densities (a white square in Fig. 3). However, the pyramidal neuron 3 generates bursting activity when the $\mathrm{sI}_{\mathrm{AHP}}$ conductance density is increased to $0.4 \mathrm{mS} / \mathrm{cm}^{2}$ with the same GABA 
conductance density, $0.015 \mathrm{mS} / \mathrm{cm}^{2}$, and total feedback loop delay, $2 \mathrm{msec}$. The duration of the bursts in the pyramidal neuron 3 is $110 \mathrm{msec}$ (Fig. 5).

The total feedback loop delay regulates the duration of the bursts in the pyramidal neuron in the type II model. Figures 6 and 7 show the duration of the bursts in the pyramidal neuron and inhibitory interneuron with different values of the total feedback loop delays, 300 msec and 650 msec. The values of $\mathrm{sI}_{\mathrm{AHP}}$ and GABA conductance densities, $\mathrm{g}_{\mathrm{sI}} \mathrm{AHP}_{\mathrm{A}}=0.4 \mathrm{mS} / \mathrm{cm}^{2}$ and $\mathrm{g}_{\mathrm{GABA}}=$ $0.015 \mathrm{mS} / \mathrm{cm}^{2}$, are the same as in Figure 5. When the total feedback loop delay is increased to $300 \mathrm{msec}$ from $2 \mathrm{msec}$ (Fig. 5) the duration of the bursts in the pyramidal neuron 3 is $394 \mathrm{msec}$ (middle panel in Fig. 6). When the total feedback loop delay is further increased to $650 \mathrm{msec}$ the duration of the bursts in the pyramidal neuron 3 is $727 \mathrm{msec}$ (middle panel in Fig. 7). Thus, the duration of the bursts in the pyramidal neuron is increased as the total feedback loop delay increases. The delayed burst in the inhibitory interneuron inhibits the pyramidal neuron causing termination of its burst and prevents next random input spike from generating burst activity in the pyramidal neuron (Figs. 6 and 7).

The duration of the bursts in the pyramidal neurons depends upon the total feedback loop delay in type II model. The total feedback loop delay of the inhibitory interneuron was varied to examine the duration of the bursts. The total feedback loop delays of the inhibitory interneuron represent all delays in connections between the pyramidal neuron 3 and inhibitory interneuron 4 in a negative feedback loop (Fig. 1). For large values of delays, $(>8 \mathrm{msec})$, the total feedback loop delays represent propagation of action potentials through multiple neurons. Figure 8 shows that the duration of the bursts in the pyramidal neuron 3 is increased as the total feedback loop delay increases (Table 1). The values of $\mathrm{sI}_{\mathrm{AHP}}$ and GABA conductance densities, $0.4 \mathrm{mS} / \mathrm{cm}^{2}$ and $0.015 \mathrm{mS} / \mathrm{cm}^{2}$, respectively, are chosen from Fig. 3 to compare the duration of the bursts in a range of the total feedback loop delay. 
Taken together, our simulations show that the slow $\mathrm{Ca}^{2+}$-activated $\mathrm{K}^{+}$current $\left(\mathrm{sI}_{\mathrm{AHP}}\right)$ can influence bursting activity in the pyramidal neurons in the type I and type II models. In the type I model of pyramidal neurons without an inhibitory interneuron, the $\mathrm{sI}_{\mathrm{AHP}}$ controls neuronal excitability in the excitatory circuit. The pyramidal neurons generate bursting activity when neuronal excitability is increased by reduction of the channel conductance density of $\mathrm{sI}_{\mathrm{AHP}}$ in the pyramidal neurons. In the type II model of the pyramidal neurons with an inhibitory interneuron, the $\mathrm{sI}_{\mathrm{AHP}}$ also influences neuronal excitability in the excitatory and inhibitory circuit, but the results are more complex. Reduction of the $\mathrm{sI}_{\mathrm{AHP}}$ conductance density for both the pyramidal neuron and inhibitory interneuron increases inhibition in this combined excitatory and inhibitory circuit. The net result is that the pyramidal neurons do not generate bursting activity when the $\mathrm{sI}_{\mathrm{AHP}}$ conductance density $\left(\mathrm{g}_{\mathrm{sI}}{ }_{\mathrm{AHP}}\right)$ is decreased because there is increased inhibition resulting

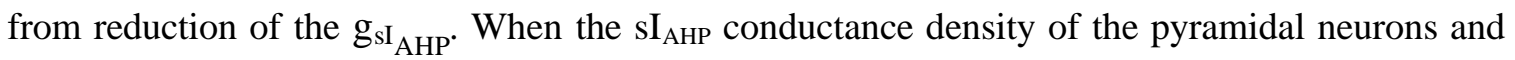
inhibitory interneuron is increased the pyramidal neurons generate bursting activity. This bursting activity results from decreased inhibition. The duration of the bursts increases as the total feedback loop delay between the pyramidal neuron and interneuron is increased.

\section{Discussion}

Although the role of $\mathrm{sI}_{\mathrm{AHP}}$ in regulating neuronal excitability is well characterized in individual cells, both excitatory and inhibitory, its role in the behavior of even simple circuits is not easily studied. This is primarily because the circuitry of even well studied brain regions (e.g. hippocampus) is highly complex and the types of channels and modulators active at different cell types cannot be simultaneously controlled experimentally. Computational studies using a simplified multicompartment neuronal circuit model, like those used here, allow the study of the effects of altering $\mathrm{sI}_{\mathrm{AHP}}$ on excitatory and inhibitory neurons in networks. 
Many neurotransmitters modulate the $\mathrm{sI}_{\mathrm{AHP}}$ through G-protein coupled receptors (Sah, 1996). The effect of these modulatory transmitters is to reduce $\mathrm{sI}_{\mathrm{AHP}}$, and consequently to increase neuronal excitability. Simulations using the type I model here show that reducing the conductance density of $\mathrm{sI}_{\mathrm{AHP}}$ in the excitatory neuron increases neuronal excitability, resulting in generating bursting activity in the pyramidal neurons, as would be expected. Thus this type I model of the excitatory circuit supports known properties of $\mathrm{sI}_{\mathrm{AHP}}$ that the $\mathrm{sI}_{\mathrm{AHP}}$ plays a role in regulating neuronal excitability in hippocampal pyramidal neurons (Borde et al., 1999 and 2000; Gao and Fung, 2002; Martin et al., 2001; Pedarzani et al., 1998).

Martin et al. (2001) showed that down-regulation of $\mathrm{sI}_{\mathrm{AHP}}$ by activation of metabotropic glutamate receptors contributes to epileptiform activity in the 4-aminopyridine model of seizures in the hippocampal slice. Blocking these receptors prevented the down regulation of $\mathrm{sI}_{\mathrm{AHP}}$ and blocked the generation of epileptiform discharges. The increased excitability caused by the lack of negative feedback provided by the increased $\mathrm{sI}_{\mathrm{AHP}}$ activity contributes to epileptiform activity.

Our simulations using the type II model show that increasing the channel conductance density of $\mathrm{SI}_{\mathrm{AHP}}$ in both the inhibitory interneuron and excitatory neurons results in decreased excitability when the GABA conductivity is small $\left(\mathrm{g}_{\mathrm{GABA}} \leq 0.010 \mathrm{mS} / \mathrm{cm}^{2}\right)$. However, for larger values of the GABA conductance density, the effect is reversed; something that might not have originally been predicted. Increasing the $\mathrm{sI}_{\mathrm{AHP}}$ conductance density causes a conversion from nonbursting to bursting activity (Fig. 3). This behavior is illustrated in Figures 4 and 5 . This important observation illustrates that increasing $\mathrm{sI}_{\mathrm{AHP}}$ activity in all cells is not always antiepileptogenic, if indeed some of the affected cells are inhibitory interneurons.

Small values of the $\mathrm{sI}_{\mathrm{AHP}}$ conductance density cause repeated spike generation in the inhibitory interneuron. With the GABA conductance density, $\geq 0.15 \mathrm{mS} / \mathrm{cm}^{2}$, inhibition resulting from these generated spikes in the inhibitory interneuron is strong enough to prevent bursting 
activity in the pyramidal neurons. When the $\mathrm{sI}_{\mathrm{AHP}}$ conductance density is increased the inhibitory interneuron generates isolated bursts instead (Fig. 5).

In these models, each burst in the pyramidal neuron (middle trace in Figs. 5-7) is followed by bursts in the inhibitory interneuron after the synaptic delay (bottom trace in Figs. 57). This burst in turn, by an inhibitory connection, inhibits the pyramidal neuron and terminates burst activity in the pyramidal neuron. The length of the burst is determined by the total delay of the feedback loop in the circuit. If there is only a single synaptic connection between the pyramidal neuron and inhibitory interneuron as shown in Fig. 1B only short bursts can be generated (Fig. 5). However, if we assume that the feedback loop may include a chain of neurons propagating action potentials the loop delay is larger, therefore, longer bursts will be generated. Figs. 6 and 7 show traces from simulations with larger delays resulting in longer bursts.

The duration of the burst in the pyramidal neurons is increased as the feedback loop delays increase as shown in Fig. 8. The loop delay consists of delays in two branches of the loop, an excitatory connection from the pyramidal neuron to inhibitory interneuron and an inhibitory connection from the inhibitory interneuron to pyramidal neuron. Different values of these delays, which result in the same total loop delay, were applied to test the dependence of bursting activity on each connection. The duration of the bursts was dependent upon the total loop delay but not each connection delay. Figure 8 and Table 1 show the durations of bursts (y) for different loop delays (x). The relationship between $\mathrm{x}$ and $\mathrm{y}$ is linear in our simulations and well fit $(\mathrm{p}<0.0001)$ by a linear equation, $\mathrm{y}=0.93 \mathrm{x}+110$ (black line).

Deyo and Lytton (1997) studied the effect of inhibition on synchronizing and desynchronizing roles using the reduced Traub network model proposed by Pinsky and Rinzel (1994). There are similarities and differences between our model and their model of pyramidal cells. In their model, there are two compartments, somatic and dendritic, with various network connections, while our model has 17 compartments with an excitatory and an inhibitory connections. The synaptic connections are randomly chosen in their model. The synaptic 
conductance and delay increase linearly as the density of synapses decreases exponentially. In our model, the synaptic delay and density of synapses are varied with constant values.

The Deyo and Lytton (1997) model shows that synchronous population burst can be disrupted by increasing the strength of interburst hyperpolarization caused by an increase of $\mathrm{sI}_{\mathrm{AHP}}$ density or the addition of a separate inhibitory interneuron pool, which has $\mathrm{sI}_{\mathrm{AHP}}$ and projected to $\mathrm{GABA}_{\mathrm{B}}$ receptor. Our model shows that bursting activity can be terminated by an increase of the $\mathrm{sI}_{\mathrm{AHP}}$ conductance density of the pyramidal neuron in the type I model of the excitatory circuit. In the type II model of the excitatory and inhibitory circuit, bursting activity can be terminated by reducing inhibition caused by the increased $\mathrm{sI}_{\mathrm{AHP}}$ conductance density of the pyramidal neuron and inhibitory interneuron. Therefore, both our and Deyo and Lytton (1997) models show that synchronizing bursting activity such as that seen in epilepsy can be modified by either $\mathrm{sI}_{\mathrm{AHP}}$ or an interneuron including $\mathrm{sI}_{\mathrm{AHP}}$.

In future studies, it would be of interest to study $\mathrm{sI}_{\mathrm{AHP}}$ channel kinetics using recent experimental data of $\mathrm{sI}_{\mathrm{AHP}}$ in the pyramidal cells. The networks in Deyo and Lytton (1997) model range in size from $100-500$ neurons with random synaptic connections. Our model has 3 pyramidal neurons and an inhibitory interneuron with an excitatory and an inhibitory connections. The sensitivity of the observed effects to network size should be tested using larger networks with a variety of synaptic connections.

These studies illustrate the ability to use model neural networks to test the multiple simultaneous influences on bursting behavior and epileptogenic activity. While the simpler of our two models yields more predictable results regarding the influences of $\mathrm{sI}_{\mathrm{AHP}}$, the addition of local network inhibition, a realistic consideration, shows that the effects of changes of $\mathrm{sI}_{\mathrm{AHP}}$ are much less intuitive. As one thinks about the influences on network behavior that might act to control abnormal bursting, it is important to recognize that agents that affect all neurons, excitatory and inhibitory, in a given network may produce different effects than those observed with simple 
excitatory systems. Indeed potential therapies must account for such complicated network interactions if the desired therapeutic effect is to be obtained.

\section{Acknowledgements}

This research is supported by NIH grant NS38958. A preliminary version of this work was presented at Computational Neuroscience 2003 meeting.

\section{References}

Alger BE and Nicoll RA (1980) Epileptiform burst afterhyperolarization: calcium-dependent potassium potential in hippocampal CA1 pyramidal cells. Science, 210:1122-4.

Beck H, Blümcke I, Kral T, Clusmann H, Schramm J, Wiestler OD, and Heinemann U (1996) Properties of delayed rectifier potassium current in dentate granule cells from the hippocampus of patients with chronic temporal lobe epilepsy. Epilepsia, 37:892-901.

Behr J, Gloveli T, and Heinemann U (2000) Kindling induces a transient suppression of afterhyperpolarization in rat subicular neurons. Brain Res., 867:259-264.

Bernard C, Cossart R, Hirsch JC, Esclapez M, Ben-Ari Y (2000) Physiological modifications in hippocampal CA1 interneuron in experimental epilepsy result in their hyperactivity. Epilepsia, 41 (Suppl 7), A.10.

Bhalla US and Bower JM (1993) Exploring parameter space in detailed single neurons models: Simulations of the mitral and granule cells of the olfactory bulb. J. Neurophysiology, 69:19481965. 
Biervert C, Schroeder BC, Kubisch C, Berkovic SF, Propping P, Jentsch, TJ, and Steinlein OK (1998) A potassium channel mutation in neonatal human epilepsy. Science, 279(1998):403-406.

Borde M, Bonansco C and Buno W (1999) The activity-dependent potentiation of the slow Ca2+activated $\mathrm{K}+$ current regulates synaptic efficacy in rat CA1 pyramidal neurons. Pflugers Arch., 437:261-6.

Borde M, Bonansco C, de Sevilla F, Le Ray D, and Buno W (2000) Voltage-clamp analysis of the potentiation of the slow $\mathrm{Ca} 2+$-activated $\mathrm{K}+$ current in hippocampal pyramidal neurons. Hippocampus, 10:198-206.

S.N. Deyo and W.W. Lytton (1997) Inhibition can disrupt hypersynchrony in model neuronal networks. Prog. Neuropsychopharmacol. Biol. Psychiatry, 21:735-50.

During MJ, Ryder KM and Spencer DD (1995) Hippocampal GABA transporter function in temporal-lobe epilepsy. Nature, 376(1995):174-7.

Empson RM and Jefferys JGR (2001) Ca2+ entry through L-type Ca2+ channels helps terminate epileptiform activity by activation of a $\mathrm{Ca} 2+$ dependent afterhyperpolarization in hippocampal CA3. Neuroscience, 102:297-305.

Freund TF and Buzsáki G (1996) Interneurons of the hippocampus. Hippocampus, 6(1996):347470.

Gao TM and Fung ML (2002) Decreased large conductance Ca(2+)-activated K(+) channel 
activity in dissociated CA1 hippocampal neurons in rats exposed to perinatal and postnatal hypoxia. Neuroscience Lett., 332:163-6.

Kwan P, Sills GJ, Brodie MJ (2001) The mechanisms of action of commonly used antiepileptic drugs. Pharmacol. Ther. 90:1-34.

Martin ED, Araque A, Buno W (2001) Synaptic regulation of the slow Ca2+-activated K+ current in hippocampal CA1 pyramidal neurons: implication in epileptogenesis. J. Neurophysiology, $86: 2878-86$

Moshe SL (2000) Mechanisms of action of anticonvulsant agents. Neurology. 55(5 Suppl 1):S3240; discussion S54-8.

McQuiston AR and Madison DV (1999) Muscarinic receptor activity induces an afterdepolarization in a subpopulation of hippocampal CA1 interneurons. J. Neuroscience, 19:5703-5710.

Olsen RW and Avoli M (1997) GABA and epileptogenesis. Epilepsia, 38:399-407.

Pedarzani P, Krause M, Haug T, Storm JF, and Stühmer W (1998) Modulation of the $\mathrm{Ca}^{2+}$ Activated $\mathrm{K}^{+}$Current $\mathrm{s} I_{\mathrm{AHP}}$ by a Phosphatase-Kinase Balance Under Basal Conditions in Rat CA1 Pyramidal Neurons. J. Neurophysiology, 79:3252-3256.

Pinsky PF and Rinzel J (1994) Intrinsic and network rhythmogenesis in a reduced Traub model for CA3 neurons. J Comput Neuroscence, 1(1994): 39-60. Erratum in: J Comput. Neuroscience, 2(1995):275. 
Prince DA (1978) Neurophysiology of epilepsy. Annu. Rev. Neuroscience, 1:395-415.

Protopapas AD, Vanier M, and Bower JM (1998) Simulating Large Networks of Neurons. In Methods in Neuronal Modeling, second edition, ed. C. Koch and I. Segev, pp. 461-498, Cambridge: MIT Press.

Sah P (1996) $\mathrm{Ca}^{2+}$-activated $\mathrm{K}^{+}$currents in neurons: types, physiological roles and modulation. Trends Neuroscience, 19:150-4, Review.

Traub RD, Jefferys JGR, Miles R, Whittington MA, and Tóth K (1994) A branching dendritic model of a rodent CA3 pyramidal neuron. J. Physiol. (Lond), 481:79-95.

Traub RD, Wong RK, Miles R, and Michelson H (1991) A model of a CA3 hippocampal pyramidal neuron incorporating voltage-clamp data on intrinsic conductances. J. Neurophysiology, 66:635-50.

Treiman DM (2001) GABAergic mechanisms in epilepsy. Epilepsia, 42 Suppl 3:8-12.

Verma-Ahuja S, Evans MS, and Pencek TL (1995) Evidence for decreased calcium dependent potassium conductance in hippocampal CA3 neurons of genetically epilepsy-prone rats. Epilepsy Res., 22:137-144.

Yang K-H, Franaszczuk PJ, and Bergey GK (2002) The influence of Synaptic Connectivity on the Pattern of Bursting Behavior in Model Pyramidal Cells. Neurocomputing, 44-46:233-242. 
Yang K-H, Franaszczuk PJ, and Bergey GK (2003) The Influences of Somatic and Dendritic Inhibition on the Patterns of Bursting in a Neuronal Circuit Model. Biological Cybernetics, in press.

Zhang L and McBain CJ (1995) Potassium conductances underlying repolarization and afterhyperpolarization in rat CA1 hippocampal interneurones. J. Physiol. 488:661-672. 

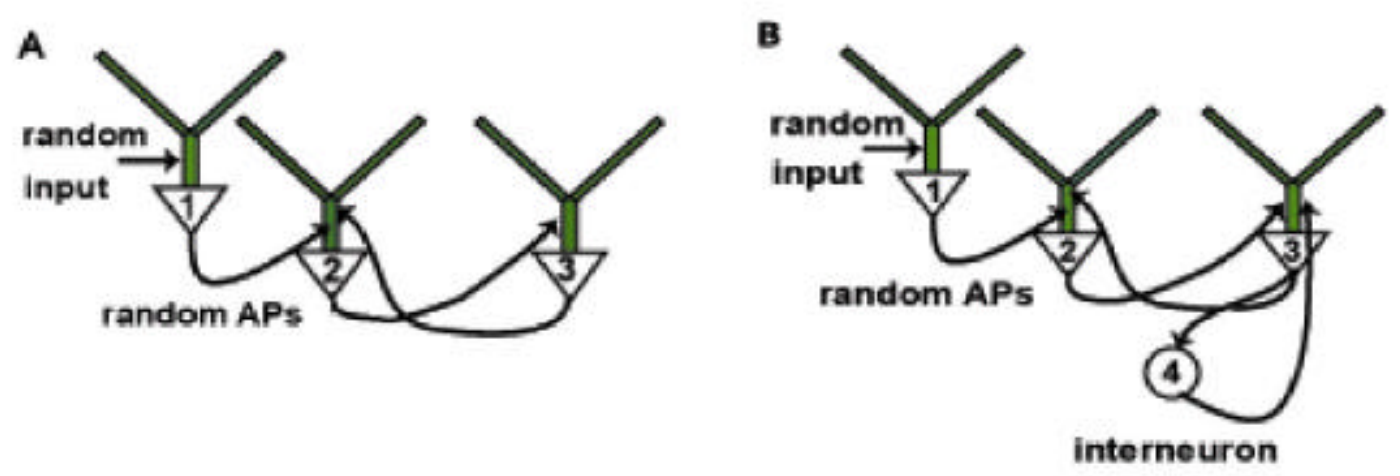

Figure 1. Schematic representation of neural circuit models. A. Type I model: neuron 2 and neuron 3 are connected by reciprocal excitatory synapses. The excitatory synaptic inputs are on the main dendrite of these two neurons. B. Type II model: an inhibitory interneuron 4 in a negative feedback loop with the pyramidal neuron 3 is added to the type I excitatory circuit in A. This inhibitory interneuron synapses on the main dendrite of neuron 3. 


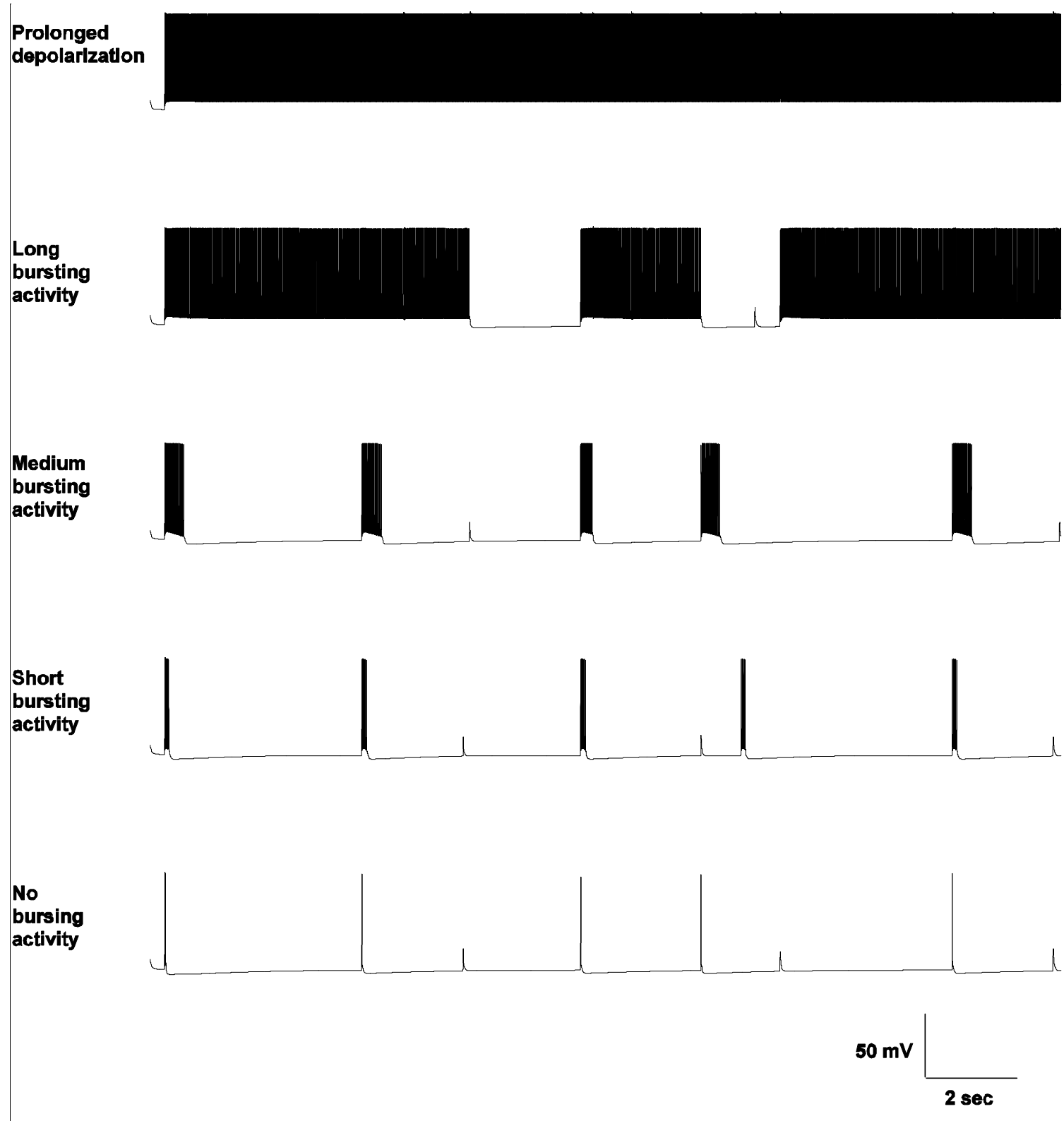

Figure 2. Classification of the patterns of bursting activity in the pyramidal neurons. Simulations were run for $20 \mathrm{sec}$. The duration of the bursts for prolonged depolarization is $19.6 \mathrm{sec}$, which is almost the entire simulation time, $20 \mathrm{sec}$. The long bursting activity has a few repeated bursts with a duration range of the bursts between $2.6 \mathrm{sec}$ and $6.6 \mathrm{sec}$. The duration of the bursts for medium bursting activity is between $210 \mathrm{msec}$ and $400 \mathrm{msec}$ with several bursts. The duration of the bursts for short bursting activity is $<200 \mathrm{msec}$ with several bursts. 


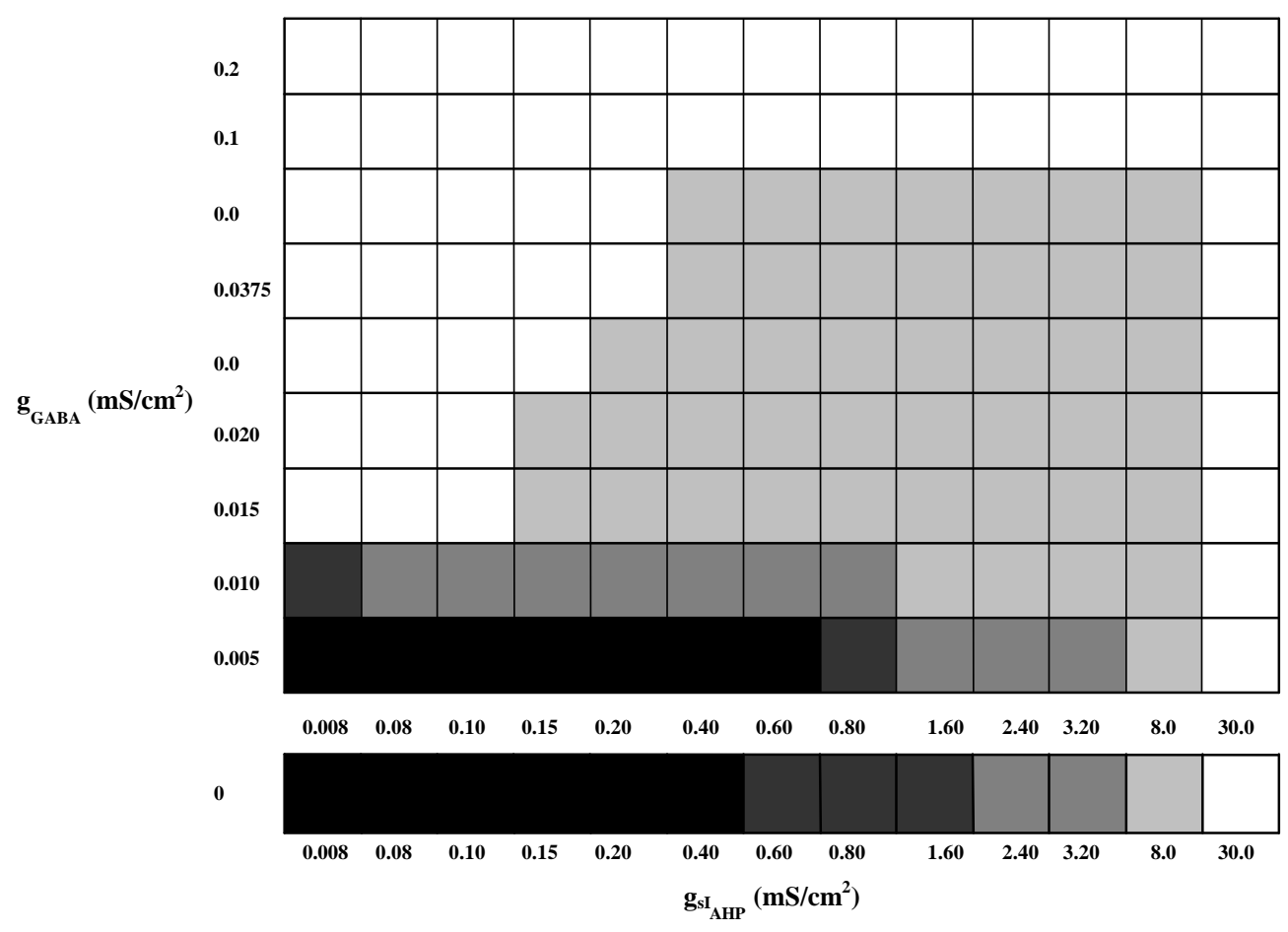

Figure 3. The effect of GABAergic inhibition and $\mathrm{sI}_{\mathrm{AHP}}$ channel conductance densities on bursting activity in the pyramidal neurons in both type I and type II models. The bottom and top panels represent results from the type I model and the type II model, respectively. The black square represents prolonged depolarization and white square represents non-bursting activity in the pyramidal neuron. For the long, medium, and short bursting activity, the shade of gray darkens from long to short bursts; PD represents prolonged depolarization, LB represents long busting activity, MB represents medium bursting activity, SB represents short bursting activity, and NB represents no bursting activity. The values of the $\mathrm{g}_{\mathrm{sI}} \mathrm{AHP}_{\mathrm{H}}$ shown were increased or decreased from $0.8 \mathrm{mS} / \mathrm{cm}^{2}$ whereas the values of the $\mathrm{g}_{\mathrm{GABA}}$ were increased from $0.005 \mathrm{mS} / \mathrm{cm}^{2}$. The values of both $\mathrm{g}_{\mathrm{sI}} \mathrm{AHP}$ and $\mathrm{g}_{\mathrm{GABA}}$ in the diagram are not at regular increments because they were selected to illustrate various changes in bursting activity. 


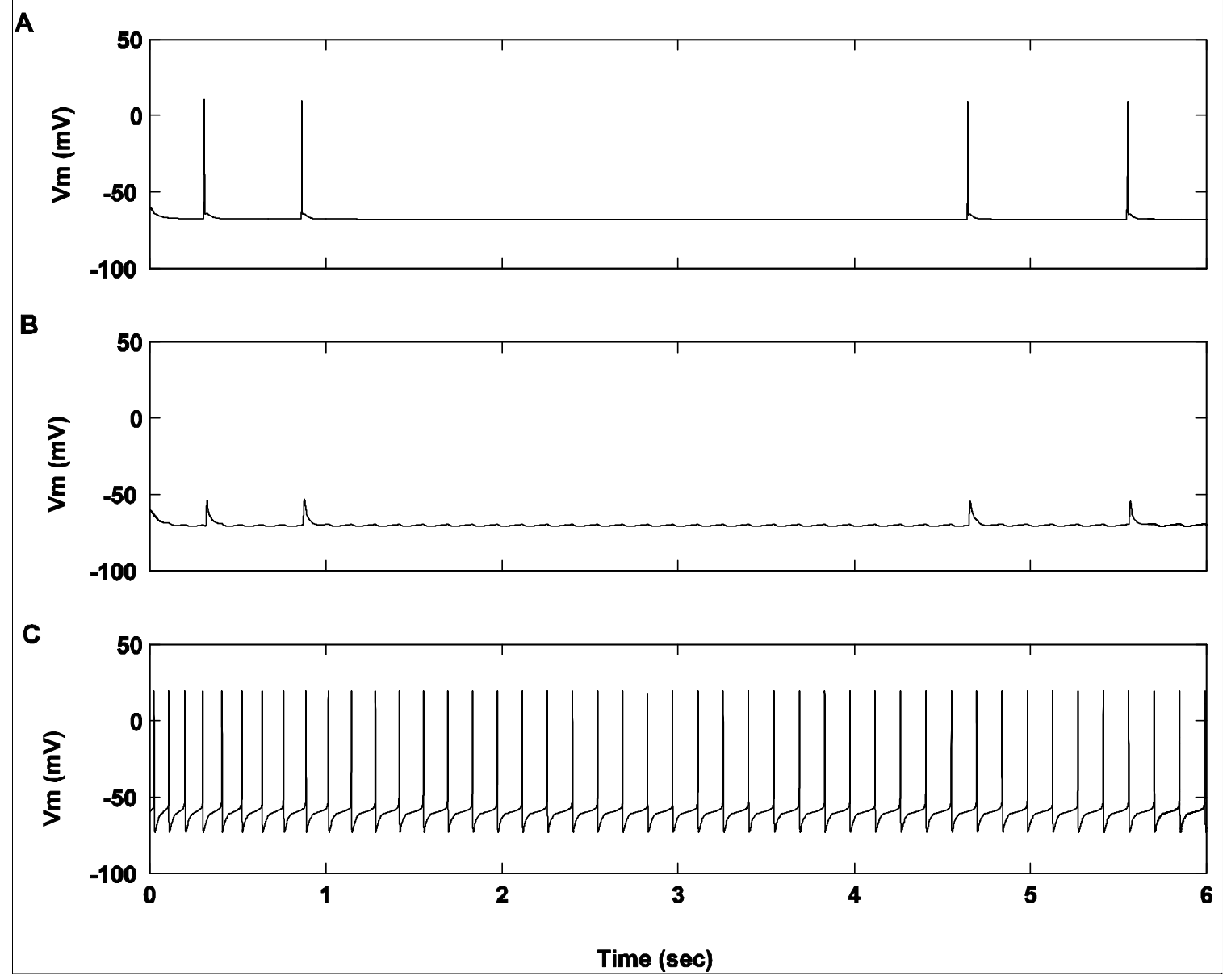

Figure 4. Traces of membrane potentials for neuron 1, neuron 3, and interneuron 4 as shown in

Fig.1B. The channel conductance densities of $\mathrm{sI}_{\mathrm{AHP}}\left(\mathrm{g}_{\mathrm{sI}} \mathrm{AHP}\right)$ and $\mathrm{GABA}\left(\mathrm{g}_{\mathrm{GABA}}\right)$ are $0.1 \mathrm{mS} / \mathrm{cm}^{2}$ and $0.015 \mathrm{mS} / \mathrm{cm}^{2}$, respectively. This result is represented as a white square (non-bursting) in Figure 3. The total feedback loop delay is $2 \mathrm{msec}$. A. Action potentials generated from random inputs in the pyramidal neuron 1 in Figure 1. B. Trace of membrane potentials in the pyramidal neuron 3 in Figure 1B. C. Trace of membrane potentials in the inhibitory interneuron 4 in Figure 1B. The inhibitory interneuron $(\mathrm{C}$, bottom trace) is firing continuously preventing the pyramidal neuron 3 ( $\mathrm{B}$, middle trace) from generating bursts in response to random action potentials from the pyramidal neuron $1(\mathrm{~A}$, top trace). 


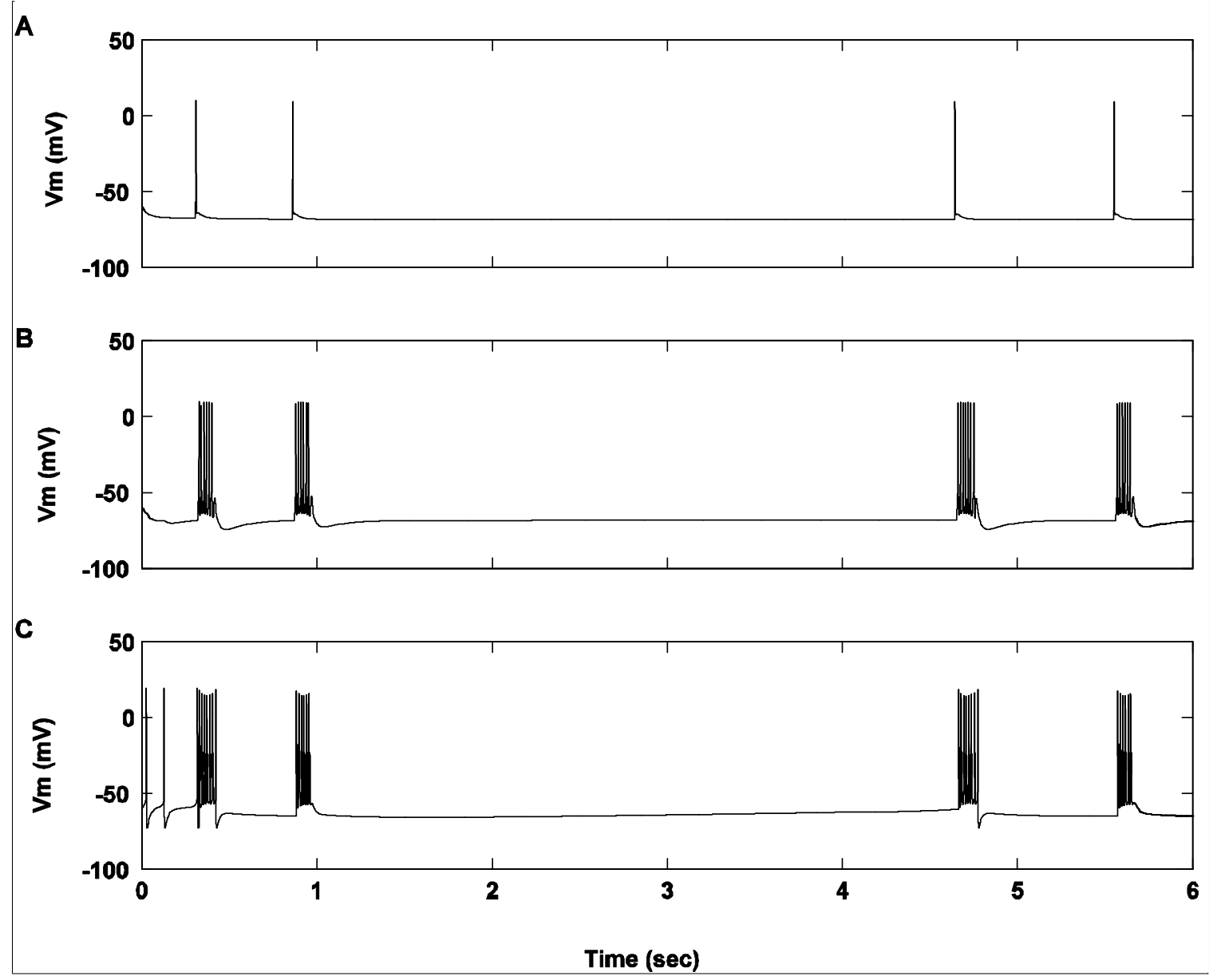

Figure 5. Traces of membrane potentials for neuron 1, neuron 3, and interneuron 4 as shown in Fig 1B. The GABA conductance density, $\mathrm{g}_{\mathrm{GABA}}=0.015 \mathrm{mS} / \mathrm{cm}^{2}$, and the total loop delay, $2 \mathrm{~ms}$, are the same but the $\mathrm{sI}_{\mathrm{AHP}}$ conductance density $\left(\mathrm{g}_{\mathrm{sI}}{ }_{\mathrm{AHP}}\right)$ is increased to $0.4 \mathrm{mS} / \mathrm{cm}^{2}$, the activity of which is represented by a light gray square (short bursting) in Fig. 3. A. Action potentials generated from random inputs in the pyramidal neuron 1 in Figure 1. B. Trace of membrane potentials in the pyramidal neuron 3 in Figure 1B. C. Trace of membrane potentials in the inhibitory interneuron 4 in Figure $1 \mathrm{~B}$. Now both the inhibitory interneuron $(\mathrm{C}$, bottom trace) and pyramidal neuron 3 (B, middle traces) exhibit bursting behavior shown as a light gray square in Fig. 3. The duration of the bursts in the pyramidal neuron 3 is $110 \mathrm{msec}$. 

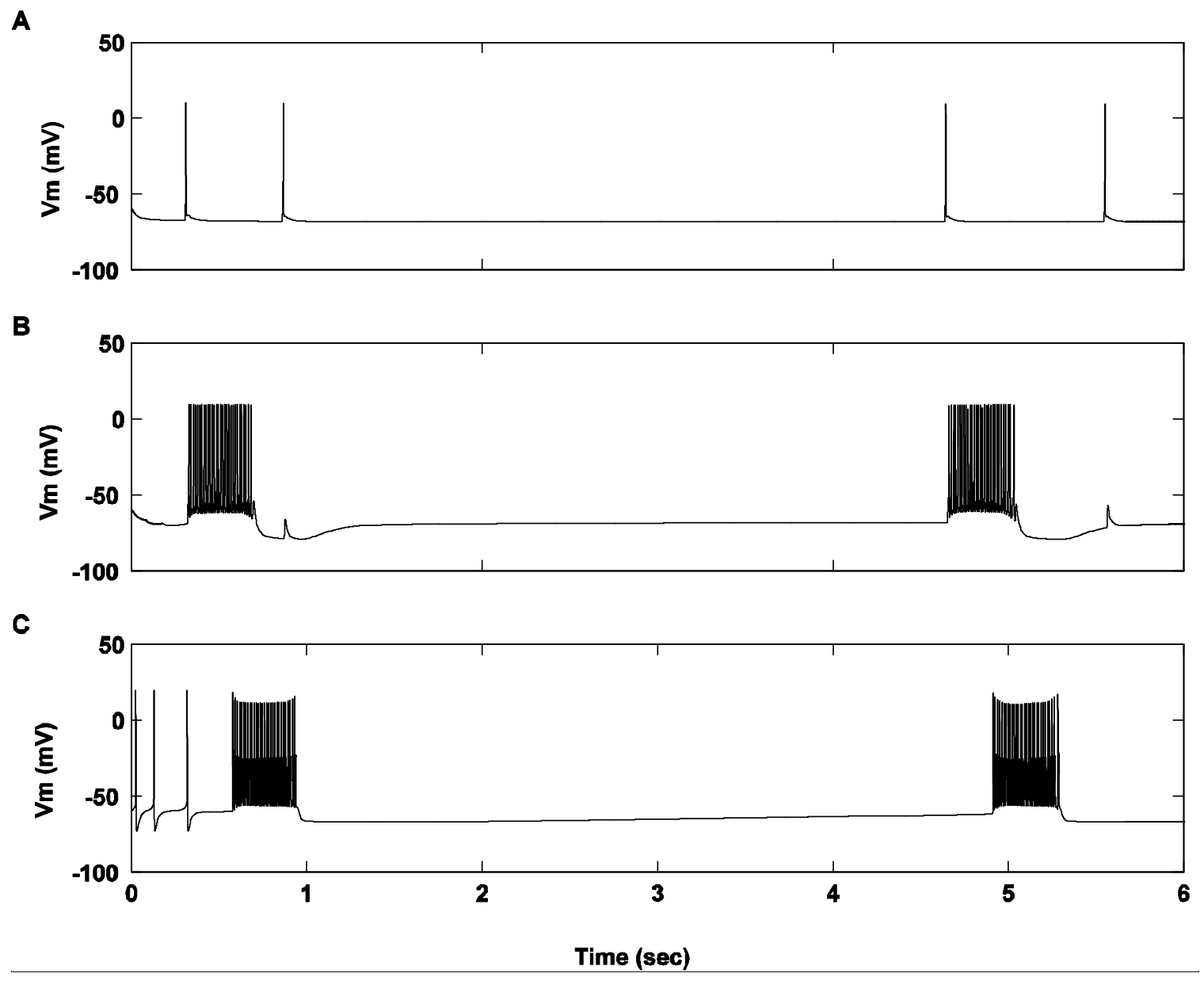

Figure 6. Traces of membrane potentials for neuron 1, neuron 3, and interneuron 4 as shown in

Fig 1B. The channel conductance densities, $\mathrm{g}_{\mathrm{sI}} \mathrm{AHP}=0.4 \mathrm{mS} / \mathrm{cm}^{2}$ and $\mathrm{g}_{\mathrm{GABA}}=0.015 \mathrm{mS} / \mathrm{cm}^{2}$, are the same as in Figure 5 but the total loop delay is increased to $300 \mathrm{msec}$. The duration of the bursts in the pyramidal neuron 3 is $394 \mathrm{msec}$. A. Action potentials generated from random inputs in the pyramidal neuron 1 in Figure 1. B. Trace of membrane potentials in the pyramidal neuron 3 in Figure 1B. C. Trace of membrane potentials in the inhibitory interneuron 4 in Figure 1B. The length of bursts is increased; the delayed burst in the inhibitory interneuron inhibits the pyramidal neuron. This inhibition on the pyramidal neuron results in termination of its burst activity and prevents the next random input spike from generating burst activity in the pyramidal neuron. 


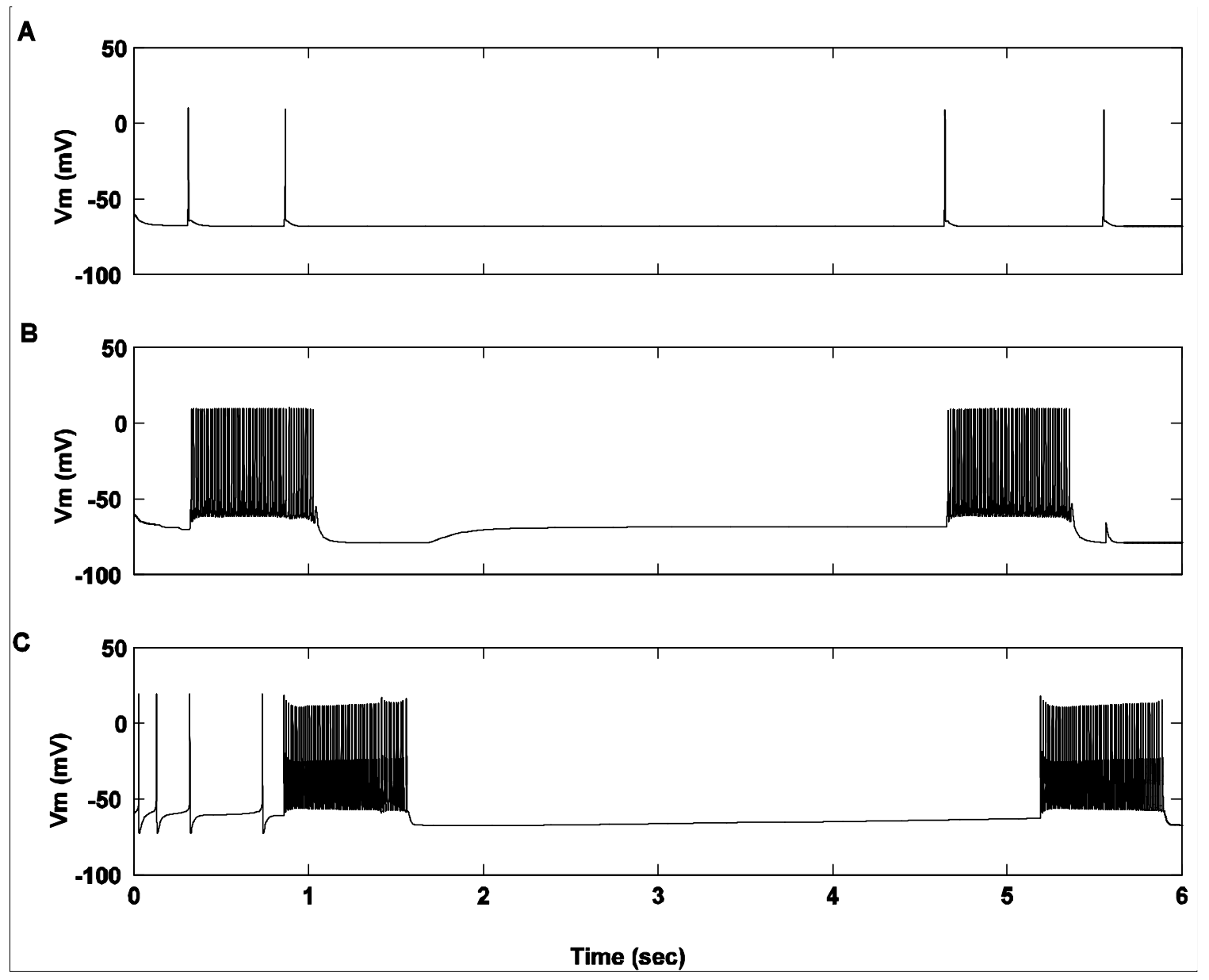

Figure 7. Traces of membrane potentials for neuron 1, neuron 3, and interneuron 4 as shown in Fig 1B. The channel conductance densities, $\mathrm{g}_{\mathrm{sI}} \mathrm{AHP}=0.4 \mathrm{mS} / \mathrm{cm}^{2}$ and $\mathrm{g}_{\mathrm{GABA}}=0.015 \mathrm{mS} / \mathrm{cm}^{2}$, are the same as in Figure 5 but the total loop delay is increased to $650 \mathrm{msec}$. A. Action potentials generated from random inputs in the pyramidal neuron 1 in Figure 1. B. Trace of membrane potentials in the pyramidal neuron 3 in Figure 1B. C. Trace of membrane potentials in the inhibitory interneuron 4 in Figure 1B. The duration of bursts in the pyramidal neuron 3 is further increased as compared with Figure 6 (727 msec in B, middle trace). 


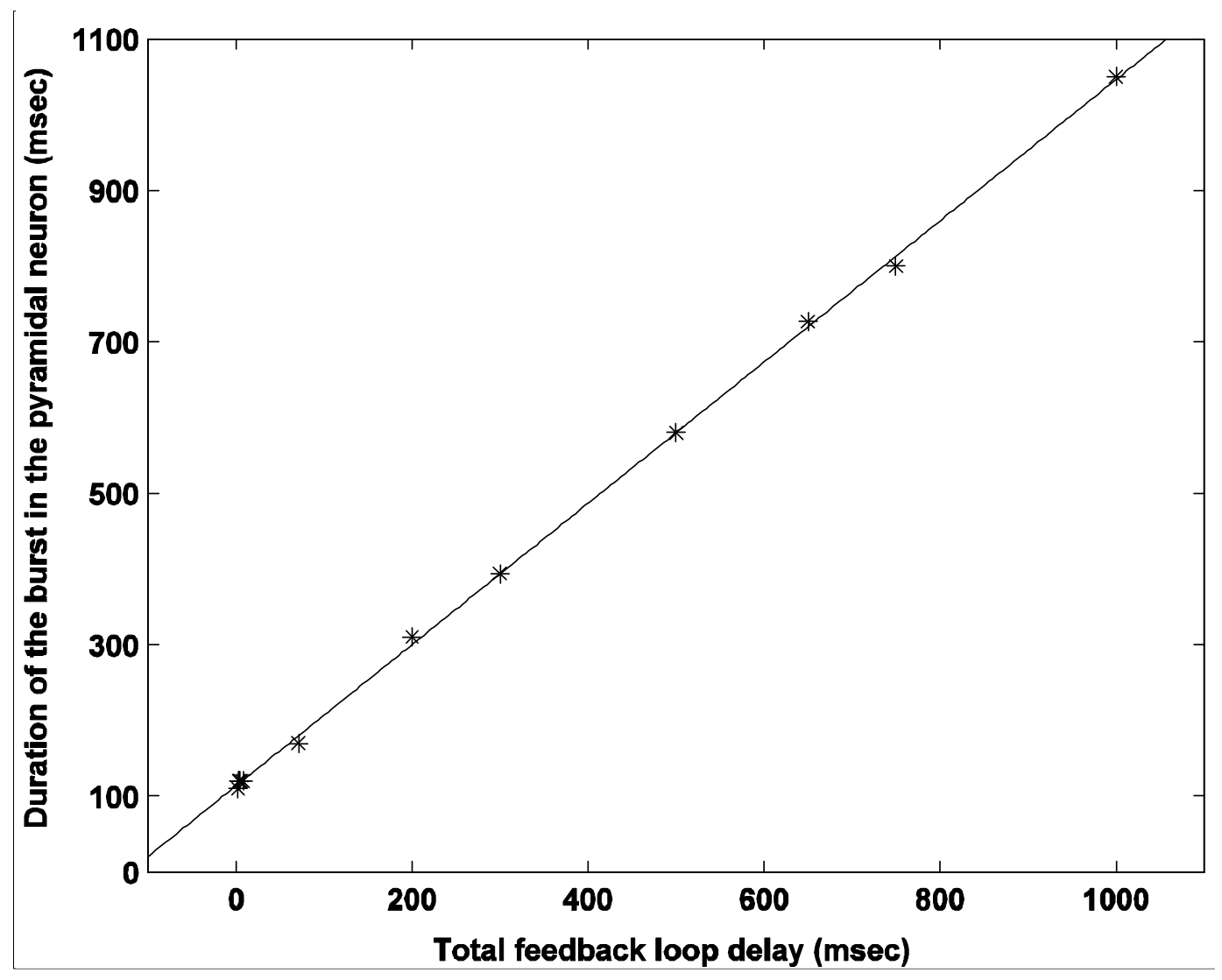

Figure 8 . The relation between duration of the burst in the pyramidal neuron 3 (vertical, y) and the total feedback loop delay (horizontal, $x)$. Data points are well fit $(\mathrm{p}<0.0001)$ by a linear equation, $\mathrm{y}=0.93 \mathrm{x}+110$ (black line). 


\section{Tables}

Table 1. Duration of the bursts for the pyramidal neuron in type II model

\begin{tabular}{|l|l|l|l|l|l|l|l|l|l|l|l|}
\hline $\begin{array}{l}\text { Total feedback loop } \\
\text { delay (msec) }\end{array}$ & 2 & 3 & 4 & 5 & 8 & 71 & 200 & 300 & 500 & 750 & 1000 \\
\hline $\begin{array}{l}\text { Duration of the } \\
\text { bursts (msec) }\end{array}$ & 110 & 120 & 120 & 120 & 120 & 170 & 310 & 400 & 580 & 800 & 1050 \\
\hline
\end{tabular}

